Article

\title{
Outcomes of Establishing an Urgent Care Centre in the Same Location as an Emergency Department
}

\author{
Annelie Raidla ${ }^{1,2}$, Katrin Darro ${ }^{1,2}$, Tobias Carlson 2,3, Amir Khorram-Manesh 2,4(1), \\ Johan Berlin ${ }^{5}$ (i) and Eric Carlström $2,6,7, *$ (i) \\ 1 Emergency Department at Östra Hospital, Sahlgrenska University Hospital, 41390 Gothenburg, Sweden; \\ annelie.raidla@vgregion.se (A.R.); katrin.darro@vgregion.se (K.D.) \\ 2 Gothenburg Emergency Research Group (GEMREG), Sahlgrenska University Hospital, \\ 41390 Gothenburg, Sweden; tobias.carlson@vgregion.se (T.C.); \\ amir.khorram-manesh@surgery.gu.se (A.K.-M.) \\ 3 Center of Emergency Department Development, Sahlgrenska University Hospital, \\ 41390 Gothenburg, Sweden \\ 4 Institute of Clinical Sciences, Sahlgrenska Academy, Gothenburg University, 40530 Gothenburg, Sweden \\ 5 Department of Social and Behavioral Studies, University West, 46186 Trollhättan, Sweden; \\ johan.berlin@hv.se \\ 6 Institute of Health and Care Sciences, Sahlgrenska Academy, University of Gothenburg, \\ 40530 Gothenburg, Sweden \\ 7 USN School of Business, Campus Vestfold, University of South-Eastern Norway, 3603 Kongsberg, Norway \\ * Correspondence: eric.carlstrom@gu.se
}

Received: 2 August 2020; Accepted: 2 October 2020; Published: 4 October 2020

check for updates

\begin{abstract}
The emergency department (ED) is one of the busiest facilities in a hospital, and it is frequently described as a bottleneck that limits space and structures, jeopardising surge capacity during Major Incidents and Disasters (MIDs) and pandemics such as the COVID 19 outbreak. One remedy to facilitate surge capacity is to establish an Urgent Care Centre (UCC), i.e., a secondary ED, co-located and in close collaboration with an ED. This study investigates the outcome of treatment in an ED versus a UCC in terms of length of stay (LOS), time to physician (TTP) and use of medical services. If it was possible to make these parameters equal to or even less than the ED, UCCs could be used as supplementary units to the ED, improving sustainability. The results show reduced waiting times at the UCC, both in terms of TTP and LOS. In conclusion, creating a primary care-like facility in close proximity to the hospitals may not only relieve overcrowding of the hospital's ED in peacetime, but it may also provide an opportunity for use during MIDs and pandemics to facilitate the victims of the incident and society as a whole.
\end{abstract}

Keywords: urgent care centre; emergency department; length of stay; surge capacity; Sweden

\section{Introduction}

The increasing number of Major Incidents and Disasters (MIDs), either natural or man-made, necessitates preparedness in both human and material resources. This has become evident during the COVID 19 pandemic, which has caused tremendous pressure on Emergency Departments (EDs) in several countries. The concept of surge capacity initiated within the immediate period after an MID or the outbreak of a pandemic has the aim of increasing the number of staff and material, as well as creating spaces and structures based on validated and tested systems and procedures. However, an expanding incident necessitates an additional surge, a so-called secondary surge capacity with the intention of utilizing other possible resources. All these measures are implemented in accordance with 
the contingency plans for each organization, including healthcare, in order to create a more flexible surge capacity [1].

Most of the hospitals call in their staff and create operational spaces. The first stage entails sending home patients who are already admitted but do not need emergency care, or those who have already been treated and who can continue their recovery at home. This stage creates new beds and spaces for incoming patients. In the second phase, extra space should be created for the admission of emergency cases. Besides the ordinary ED, another admission unit is normally set up to handle either urgent patients or ordinary, non-emergency cases. An outpatient department is usually used. Whilst adequate, this approach needs to be planned as there is a clear need for staff who are familiar with the locales, equipment that has to be adjusted to emergency requirements, and procedures that can be put in place as quickly as possible based on disaster medicine principles [2].

Previous studies have shown that staff who lack such familiarity can cause more harm than save lives, and unfavourable spaces can cause more challenges than facilitating the process. In particular, EDs should have staff qualified in emergency medicine, areas for triage and sorting, and proper devices for the care of the severely injured. The optimum suggestion is actually an existing unit that already handles emergency cases, i.e., a secondary ED [3-6].

The emergency department is one of the hospital's busiest facilities and is frequently described as a bottleneck that limits space and structures, jeopardising surge capacity $[7,8]$. In recent decades, overcrowding in emergency departments (EDs) has been reported as an increasingly worrying occurrence $[9,10]$. It has been associated with longer waiting times prior to treatment for severely ill patients, risk of in-hospital mortality and a higher probability of leaving the ED against medical advice or without being seen [11]. During the height of the COVID 19 epidemic in Europe and the US in spring 2020, EDs experienced a tremendous peak in the number of patient presentations. Preparedness for disasters became a significant concern in relation to health-care sustainability, and several city-based hospitals throughout the world were operating at or near to capacity limits [12].

The issue of everyday overcrowding of EDs and the impact on preparedness to handle peaks such as that during COVID 19 appeared to be complex, with several factors including physical distancing, use of personal protective equipment and hygienic measures needing to be considered along with remedies required [13].

In the early 1980s, an increasing number of emergency cases led to the establishment of Urgent Care Centres (UCCs) [14]. They function as a healthcare provider staffed by primary care physicians, registered nurses and nurse practitioners, with the ability to handle emergency conditions that do not need ED amenities. UCCs are often managed by a hosting hospital and share mutual support systems such as laboratory, radiation and medical services. It has been reported that UCCs reduce the overuse of EDs by up to $48 \%$ [15]. Doran showed that patients treated by UCCs, sited together with and in close collaboration with an ED, received swift service and better follow-up than the control group in the study [16]. UCCs and EDs have also proven to be horizontally integrated and collaborative and function informally between ED and UCC staff [17].

This paper suggests that UCCs may be suitable units for beneficial use both in peacetime and during an MID. They fulfil the function as a supportive unit in peacetime, and by using the same staff and resources can easily be converted to an extra ED or a pandemic admission unit as evidenced by the current need during the COVID 19 epidemic. With the first UCC having been set up in Sweden, the aim of this study was to investigate the outcome of treatment in the ED versus the UCC in terms of quality, LOS, time to physician (TTP), use of medical services, referrals, revisits, hospitalisation, mortality and costs. If it was the case that these parameters were equal to the ED, the UCC could be used as a complementary unit to the ED, improving sustainability not only in peacetime but also during MIDs.

\section{Methods}

The ED and UCC studied were situated in a hospital in Gothenburg in western Sweden. The ED was part of a University Hospital, distributed over three main hospital complexes in different districts, 
with one ED each. Each of the EDs received approximately one-third of the 150,000 presentations annually in the city. The ED included was typical, i.e., treating diseases and injuries from age 16, excluding orthopaedic and psychiatric diseases. It received 53,840 visits during 2018, an increase of $4.8 \%$ over the year before (2017). The trend of more visits had been apparent during the last few decades. The ED served the part of the county characterised by the weakest socioeconomic status and highest proportion of immigrants. A UCC was established in spring 2018, staffed with primary care physicians and registered nurses. The UCC shared the triage line with the ED, with attendees being assessed post-triage as either ED or UCC patients. The UCC was expected to optimise shared resources and provide improved services for low-urgency patients. The study was approved by the Regional Ethical Review Board in Gothenburg with approval number: D 374-18.

\subsection{Sample}

The study was based on 200 patients fulfilling the inclusion criteria for visiting the UCC. The exclusion criteria were patients triaged red, patients with a preliminary diagnosis in most cases referred from the primary care centre to the ED (e.g., potential distal deep vein thrombosis, emergent vertigo etc.) and patients with a preliminary diagnosis potentially developing from non-red triage to a state of emergency (e.g., suspected ectopic pregnancy, dyspnoea, suspected urosepsis, etc.). A list of exclusion criteria based on a literature review was developed and implemented as a selective tool used in the triage at the ED. The STROBE checklist (strengthening the communication of observational studies in epidemiology) was used to guide the study process [18].

The first half ( $n=100)$ of the 200 patients were selected retrospectively on a consecutive basis just prior to the UCC being established. Consequently, the first half were treated by the ED. The second half of the patients $(n=100)$ were selected consecutively from patients triaged to the UCC six months after it was established. No other substantial changes in organization or methods occurred at the ED during the study period.

The 200 patients were distributed over 104 men and 96 women, with an average age of 45 $(S D=20.24)$. The study size was based on a power estimation of a standardized statistical power of 0.80 and medium effect size of 0.3 premeditated the appropriate sample size to 93 participants in each population. The $\alpha$ significance level was 0.05 [19]. The two populations were compared in order to concur in terms of emergency and severity. They were triaged on a five-level scale from red (highest degree of emergency) to blue (non-urgent). The distribution was red $=0$, orange $=3$, yellow $=107$, green $=89$ and blue $=13$ patients. The patients were all triaged according to the Rapid Emergency Triage Treatment Scale [20]. The most common symptoms were wounds/burns, headache/dizziness, fever/infection and chest pain/vascular symptoms (Table 1).

Table 1. Symptoms distributed over the two samples, before (ED population) and after (UCC population). $(n=200)$.

\begin{tabular}{cccc}
\hline & Before (ED) & After (UCC) & Total \\
\hline Headache/Dizziness & 20 & 8 & 28 \\
\hline Infection/Fever & 15 & 11 & 26 \\
\hline Wound/Burn & 14 & 16 & 30 \\
\hline Dyspnoea & 8 & 1 & 9 \\
\hline Abdominal & 7 & 8 & 15 \\
\hline Colorectal & 7 & 7 & 14 \\
\hline Urology & 7 & 8 & 15 \\
\hline Extremities & 7 & 9 & 16 \\
\hline Chest pain/Vascular & 5 & 14 & 19 \\
\hline Unspecific & 10 & 18 & 28 \\
\hline All & 100 & 100 & 200 \\
\hline
\end{tabular}




\subsection{Analysis}

We produced a before ( $n=100 \mathrm{ED}$ patients) and after ( $\mathrm{N}=100$ UCC patients) design, i.e., prior and after the UCC being established. Focus was on dimensions concerning the outcome of treatment at the ED in comparison to the UCC. Aspects studied were LOS, TTP, use of medical services (radiology, laboratory analysis), revisits, hospitalisations, mortality and cost. Descriptive statistics included central tendency and dispersion. LOS was defined as the time spent from admission to discharge from the UCC or the ED or admission to a ward. TTP was defined as the time spent from admission to seeing a physician. Paired-sample calculations of LOS, TTP and laboratory analysis showed a statistical difference of means. However, the results of normality measured by the Kolmogorov Smirnov test did indicate LOS, TTP and laboratory analysis to be significantly skewed (LOS sig. 0.00, TTP sig. 0.00 , and laboratory analysis sig. 0.00 ). The samples could consequently not be regarded as normally distributed due to outliers. A complementary non-parametric test was therefore conducted using a Wilcoxon signed-rank test.

\section{Results}

The results include aspects (mainly LOS, TTP and laboratory analysis) of patients visiting the UCC versus visiting the ED, a Wilcoxon signed-rank test of LOS, TTP and laboratory analysis and the cost in Euros/average attendee at the UCC versus the ED.

Several differences appeared when comparing the first and second half of the sample (treated by the ED versus treated by the UCC). From arrival to discharge, the UCC patients spent an average of $2.11 \mathrm{~h}$ less at the hospital than the ED patients. TTP was thus $1.57 \mathrm{~h}$ less at the UCC than at the ED. There was also a reduction in terms of laboratory analysis at the UCC compared to the ED. Even though the numbers of radiology, findings, referrals, revisits and hospitalisations were minor ( 26 and below), the sample visiting the UCC appeared to be almost similar to the one visiting the ED (Table 2).

Table 2. Aspects studied of patients visiting the UCC versus patients visiting the ED $(N=200)$.

\begin{tabular}{cccc}
\hline & ED & UCC & All \\
\hline $\mathrm{n}$ & 100 & 100 & 200 \\
\hline LOS (SD) & $3.21(2.32)$ & $1.10(0.63)$ & $2.15(2.00)$ \\
\hline TTP (SD) & $2.14(2.28)$ & $0.57(0.46)$ & $1.36(1.82)$ \\
\hline Laboratory analysis (SD) & $449(5.15)$ & $31(0.66)$ & $480(4.22)$ \\
\hline Radiology & 9 & 4 & 13 \\
\hline Radiology findings & 1 & 3 & 4 \\
\hline Referrals & 26 & 21 & 47 \\
\hline Revisits 72 Hours & 3 & 1 & 4 \\
\hline Hospitalisation & 1 & 0 & 1 \\
\hline 5-day Mortality & 0 & 0 & 0 \\
\hline
\end{tabular}

LOS, TTP and laboratory analyses were selected for the Wilcoxon rank test, confirming both LOS and TTP to be significantly more time consuming at the ED than at the UCC. A similar result emerged with regard to laboratory analysis.

Total cost of attendees at the UCC and the ED differed. The cost of UCC attendees was less than the cost of ED attendees (Table 4). (Table 3).

On average, an UCC attendee was 67-210 Euros cheaper. One reason for the difference was fewer medical services, i.e., radiology and laboratory than at the ED. The total cost of medical services at the UCC for the population studied was an average of 37.28 Euros less than at the ED (radiology $=16.62$, laboratory $=20.66)($ Table 4$)$. 
Table 3. Ranks and statistics of LOS, TTP and laboratory analysis of attendees at UCC versus ED $(\mathrm{N}=200)$.

\begin{tabular}{|c|c|c|c|c|}
\hline \multirow{6}{*}{$\begin{aligned} \mathrm{Z} \text { based on positive ranks } & =-7.547 \\
\text { Assympt Sig. }(2 \text {-tailed }) & =0.00\end{aligned}$} & Ranks & $\mathbf{n}$ & Mean Rank & Sum of Ranks \\
\hline & Negative Ranks & 82 (UCC LOS < ED LOS) & 55.23 & 4474.00 \\
\hline & Positive Ranks & 16 (UCC LOS > ED LOS) & 17.44 & 279.00 \\
\hline & Ties & $2($ UCC LOS = ED LOS $)$ & & \\
\hline & Total & 100 & & \\
\hline & Ranks & n & Mean Rank & Sum of Ranks \\
\hline \multirow{5}{*}{$\begin{aligned} \mathrm{Z} \text { based on positive ranks } & =-6.928 \\
\text { Assympt Sig. }(2 \text {-tailed }) & =0.00\end{aligned}$} & Negative Ranks & 80 (UCC TTP < ED TTP) & 56.75 & 4540.00 \\
\hline & Positive Ranks & 20 (UCC TTP > ED TTP) & 25.50 & 510.00 \\
\hline & Ties & $0(\mathrm{UCC}$ TTP $=$ ED TTP $)$ & & \\
\hline & Total & 100 & & \\
\hline & Ranks & n & Mean Rank & Sum of Ranks \\
\hline \multirow{4}{*}{$\begin{aligned} \mathrm{Z} \text { based on positive ranks } & =-6.723 \\
\text { Assympt Sig. }(2 \text {-tailed }) & =0.00\end{aligned}$} & Negative Ranks & 63 (UCC lab. < ED lab.) & 36.05 & 2271.00 \\
\hline & Positive Ranks & 5 (UCC lab. > ED lab.) & 15.00 & 75.00 \\
\hline & Ties & 32 (UCC lab. = ED lab.) & & \\
\hline & Total & 100 & & \\
\hline
\end{tabular}

Table 4. Cost in Euros/average attendee at the UCC and the ED distributed in total cost, radiology cost and laboratory cost.

\begin{tabular}{cccc}
\hline & $\begin{array}{c}\text { Total Cost/Average } \\
\text { Attendee }\end{array}$ & $\begin{array}{c}\text { Radiology Cost/Average } \\
\text { Attendee in the Population } \\
\text { Studied (N = 200) }\end{array}$ & $\begin{array}{c}\text { Laboratory Cost/Average } \\
\text { Attendee in the Population } \\
\text { Studied (N = 200) }\end{array}$ \\
\hline $\mathrm{ED}(n=100)$ & $\begin{array}{c}362 \mathrm{E} \text { (Physician) } \\
219 \mathrm{E}(\text { Nurse) }\end{array}$ & $18.11 \mathrm{E}$ & $22.19 \mathrm{E}$ \\
\hline $\mathrm{UCC}(n=100)$ & $\begin{array}{c}152 \mathrm{E} \text { (Physician } \\
\text { and Nurse) }\end{array}$ & $1.49 \mathrm{E}$ & $1.53 \mathrm{E}$ \\
\hline
\end{tabular}

\section{Discussion}

This study shows that waiting times for the patients studied who were referred to the UCC were reduced, both in terms of TTP and LOS. There was also a reduction in the number of blood tests performed at the UCC. Accordingly, there was a substantial cost reduction for UCC visits compared to the ED on the studied population. These components contribute to cost-effective and sustainable care. However, the sample was too small to draw any conclusions regarding the outcome in terms of assessment and treatment accuracy, though it was not possible to register any increase in revisits.

The most important effect was probably the reduced LOS. The UCC relieved the ED of low-urgency patients and, in the long run, potential crowding. This might consequently have contributed to fewer complex and diversified assignments at the ED. Extrapolating the results, a consequence of establishing a UCC might contribute to EDs maintaining their focus on emergencies and avoid time-consuming challenges such as maintaining continuity and follow-up routines [21]. The UCC studied cut the LOS by two-thirds in relation to the population studied, which may improve disaster preparedness [22]. An integrated UCC/ED may also be used as a fast track and flexible area of care during pandemic peaks and emergencies [23,24].

It can tentatively be suggested that one more important function of UCC in crisis is its networking capacity as part of the primary care system. Non-urgent and non-MID patients can easily be referred to other primary care centres for follow-up [1]. Patients who have access to continuous primary care are known to have an improved health status and lower rates of unnecessary hospitalisation compared to those which do not have such access [25]. In contrast, crowding in the emergency room not only 
contributes to patient dissatisfaction, but it also increases the risk of spread of infection, misdiagnosis and delayed administration of drugs and, in the long run, prolongs hospitalisation [22].

The proximity of the UCC used in this study seems to be an advantage, not only for peacetime use but also for a future MID, when immediate staff and material and structures are essential factors in successful MID management. The close distance between the UCC and the ED may not only alleviate the ED's burdens but also improve close interprofessional collaboration between colleagues from both units. A study four months after the establishment of an integrated ED/UCC reported inter-organizational and inter-professional collaboration. The staff, physicians and nurses crossed a stairwell and a corridor to discuss common challenges. Questions about the parties' capacity for diagnosing and treating patients were sorted out, and non-conventional solutions were occasionally invented to handle strenuous situations and tricky cases. Mistakes in assessments and patients whose health conditions rapidly changed could easily be handled by swift re-referrals from the UCC back to the ED [17].

The differences observed in this study regarding the utilization of medical services by UCC and ED on a similar population may simply reflect the ability of UCC to adjust to new conditions, procedures and perspectives when assessing patients. The ED staff may be more focused on recent symptoms and a rapidly emerging illness. The UCC staff, on the other hand, may be focused on long-term medical history [26]. While the ED assesses and reassesses the patient in a broad manner, the UCC may use anamnesis and bedside information to construct a picture of the status of the patient [16]. However, when comparing the strengths of the two units, the UCC has the potential to optimize care for both urgent and non-urgent patients. The difference in working methods can be considered an asset when providing sustainable care to the mix of needs in the population of attendees, and during pandemics and disaster management [27]. Despite fewer blood tests and X-rays at the UCC, the results obtained did not indicate any incorrect assessments or treatments at UCC. However, generalising the results of this study will require studies of larger populations. Placing a UCC close to an ED may, however, become a promising establishment in terms of reduction in costs, LOS, TTP and the use of medical services, which is beneficial in the management of an MID.

The pressure on EDs during COVID 19 underscores the need for further studies on interventions aiming to relieve and facilitate ED capacity. Even though a silver bullet for the issue of ED crowding has not yet been found, different methods may be combined to improve preparedness. UCCs are one promising method when it comes to preparedness, along with cost-reductions and improved continuity.

\section{Limitations}

As already mentioned, this is a study of a limited population from a single UCC. If the results are to be generalised, a substantial study population from several UCCs will be desirable.

This study did not include a follow-up on patient satisfaction. The next study on the outcome of the UCC established should include such a study. Even though there are reasons to believe that patients perceive the UCC as a favourable alternative to the ED, based on the shorter TTP and LOS, other factors such as treatment, follow-up and expectations may impact on patient satisfaction. Such satisfaction is also important for non-MID patients seeking help during a major emergency. It is important that the public feel secure and that patient safety for non-MID patients can be guaranteed by using ordinary staff, material and structures. Another limitation is the scarcity of research related to hospital-based UCCs, especially in a European context. Hopefully, this limited study might inspire other researchers to conduct new research on UCCs in order to improve the sustainability of healthcare.

\section{Conclusions}

In conclusion, Major Incidents and Disasters (MIDs) and pandemics such as COVID 19 are inevitable and demand hospital and prehospital preparedness in order to guarantee and enhance the capability of healthcare to save lives. Hospitals need to surge capacity by obtaining the necessary staff, material and structure, as well as valid and tested systems. Professional, trained staffs are an 
important factor in successful MID management; however, their familiarity with the facility in which they work and the devices they need to use is also essential. In this perspective, creating a primary care-like facility in close proximity to the hospitals may not only relieve overcrowding in hospital EDs in peacetime, but it also provides an opportunity for such units to be used to facilitate care of the victims of MIDs and pandemics.

Author Contributions: Conceptualization, A.R., K.D., T.C., A.K.-M, J.B., E.C.; methodology, E.C., A.R. and K.D.; Writing—original draft, E.C., A.R., K.D., A.K.-M.; Writing—review and editing, A.R., K.D., T.C., A.K.-M., J.B., E.C.; supervision, E.C. All authors have read and agreed to the published version of the manuscript.

Funding: This research was not funded.

Conflicts of Interest: The authors declare no conflict of interest.

\section{References}

1. Khorram-Manesh, A. Flexible surge capacity-Public health, public education, and disaster Management. Health Promot. Perspect. 2020, 10, 175-179. [CrossRef] [PubMed]

2. Khorram-Manesh, A.; Lönroth, H.; Rotter, P.; Wilhelmsson, M.; Aremyr, J.; Berner, A.; Nero Andersson, A.; Carlström, E. Non-medical aspects of civilian-military collaboration in management of major incidents. Eur. J. Trauma Emerg. Surg. 2017, 43, 595-603. [CrossRef] [PubMed]

3. Khorram-Manesh, A.; Yttermyr, J.; Sörensson, J.; Carlström, E. The impact of disaster and major incidents on vulnerable groups: Risk and medical assessment of patients with advanced care at home. Home Health Care Manag. Pract. 2017, 29, 183-190. [CrossRef]

4. Ablah, E.; Konda, K.S.; Konda, K.; Melbourne, M.; Ingoglia, J.N.; Gebbie, K.M. Emergency preparedness training and response among community health centers and local health departments: Results from a multi-state survey. J. Community Health 2010, 35, 285-293. [CrossRef] [PubMed]

5. Jacobs, L.M.; McSwain, N.E.; Rotondo, M.F.; Wade, D.; Fabbri, W.; Eastman, A.L.; Butler, F.K.; Sinclair, J. Improving survival from active shooter events: The Hartford Consensus. J. Trauma Acute Care Surg. 2013, 74, 1399-1400. [CrossRef] [PubMed]

6. Shoaf, K.I.; Rottman, S.J. The role of public health in disaster preparedness, mitigation, response, and recovery. Prehospital Disaster Med. 2000, 15, 144-146. [CrossRef]

7. Berlin, J.; Carlström, E. The 20-minutes Team.-A critical study from the emergency room. J. Eval. Clin. Pract. 2008, 14, 569-576. [CrossRef]

8. Berlin, J.; Carlström, E. From Artefact to Effect.-The organising effect of artefacts on teams. J. Health Organ. Manag. 2010, 24, 412-427. [CrossRef]

9. Carter, E.; Pouch, S.M.; Larson, E.L. The Relationship between Emergency Department Crowding and Patient Outcomes: A Systematic Review. J. Nurs. Scholarsh. 2014, 46, 106-115. [CrossRef]

10. Kellerman, A.L. Crisis in the emergency department. N. Engl. J. Med. 2006, 355, 1300-1303. [CrossRef]

11. Bernstein, S.L.; Aronsky, D.; Duseja, R.; Epstein, S.; Handel, D.; Hwang, U.; McCarthy, M.; McConnell, K.J.; Pines, J.M.; Rathlev, N.; et al. The Effect of Emergency Department Crowding on Clinically Oriented Outcomes. Acad. Emerg. Med. 2009, 16, 1-10. [CrossRef] [PubMed]

12. Rosovski, R.P.; Andonian, J.S.; Hayes, B.D. The impending storm: COVID-19, pandemics and our overwhelmed emergency departments. Am. J. Emerg. Med. 2019, 38, 1270-1294.

13. Khorram-Manesh, A.; Carlström, E.; Hertelendy, A.J.; Goniewicz, K.; Casady, C.B.; Burkle, F.M. Does the prosperity of a country play a role in COVID 19 outcomes? Disaster Med. Public Health Prep. 2020, 12, 1-10. [CrossRef] [PubMed]

14. Weinick, R.M.; Bristol, S.J.; DesRoches, C.M. Urgent care centers in the US: Findings from a national survey. BMC Health Serv. Res. 2009, 9, 79. [CrossRef]

15. Yee, T.; Lechner, A.E.; Boukus, E.R. The surge in urgent care centers: Emergency department alternative or costly convenience. Res. Brief 2013, 26, 1-6.

16. Doran, K.M.; Raven, M.C.; Rosenheck, R.A. What drives frequent emergency department use in an integrated health system? National data from the veterans' health administration. Annu. Emerg. Med. 2013, 62, 151-159. [CrossRef] 
17. Wennman, I.; Wittholt, M.; Carlström, E.; Carlsson, T.; Khorram-Manesh, A. Urgent care centre in Sweden-The integration of teams and perceived effects. Int. J. Health Plan. Manag. 2019, 34, 1-12. [CrossRef]

18. Vandenbroucke, J.; von Elm, E.; Altman, D.G.; Gøtzsche, P.C.; Mulrow, C.D.; Pocock, S.J. Strengthening the Reporting of Observational Studies in Epidemiology (STROBE): Explanation and Elaboration. PLoS Med. 2007, 4, 1628-1654. [CrossRef]

19. Cohen, J. Statistical Power Analysis for the Behavioral Sciences; Academic Press: Cambridge, MA, USA, 2013.

20. Wireklint, S.C.; Elmqvist, C.; Parenti, N.; Göransson, K.E. A descriptive study of registered nurses' application of the triage scale RETTSC; a Swedish reliability study. Int. Emerg. Nurs. 2018, 38, 21-28. [CrossRef]

21. Raidla, A.; Dárro, K.; Carlson, T.; Carlström, E. Characterising double frequent users in an emergency department. J. Hosp. Adm. 2018, 7, 35-39. [CrossRef]

22. Wickman, L.; Svensson, P.; Djärv, T. Effect of crowding on length of stay for common chief complaints in the emergency department: A STROBE cohort study. Medicine 2017, 96, e8457. [CrossRef] [PubMed]

23. Wennman, I.; Nordling, P.; Herlitz, J.; Lernfelt, B.; Kihlgren, M.; Gustafsson, C.; Hansson, P.-O. The clinical consequences of a prehospital diagnosis of stroke by the emergency medical services. A pilot study. Scand. J. Trauma Resusc. Emerg. Med. 2012, 20, 48. [CrossRef] [PubMed]

24. Morley, C.; Unwin, M.; Peterson, G.M.; Stankovich, J.; Kinsman, L. Emergency department crowding: A systematic review of causes, consequences and solutions. PLoS ONE 2018, 13, e0203316. [CrossRef] [PubMed]

25. O'Malley, A.S.; Forrest, C.B.; Politzer, R.M.; Wulu, J.T.; Shi, L. Health center trends, 1994-2001: What do they portend for the federal growth initiative? Health Aff. 2005, 24, 465-472. [CrossRef]

26. Tricco, A.C.; Antony, J.; Ivers, N.M. Effectiveness of quality improvement strategies for coordination of care to reduce use of healthcare services: A systematic review and meta-analysis. Can. Med. Assoc. J. 2014, 186, E568-E578. [CrossRef]

27. Wertheimer, B.; Jacobs, R.E.A.; Baily, M. Discharge before noon: An achievable hospital goal. J. Hosp. Med. 2014, 9, 210-214. [CrossRef]

(C) 2020 by the authors. Licensee MDPI, Basel, Switzerland. This article is an open access article distributed under the terms and conditions of the Creative Commons Attribution (CC BY) license (http://creativecommons.org/licenses/by/4.0/). 